\title{
Siringocistadenoma Papilífero de Localização Atípica
}

Thainá Gonçalves, Renata Cavalcante, Renata Okajima, Arival de Brito, Maraya Bittencourt (B)

Universidade Federal do Pará, Belém-Pará, Brasil

RESUMO - O siringocistadenoma papilífero é um tumor benigno anexial raro, comummente localizado no segmento cefálico e geralmente associado a um nevo sebáceo. Clinicamente a lesão não é específica mas o seu aspecto histopatológico é considerado característico. A remoção cirúrgica é o tratamento definitivo. A ocorrência desta lesão na mama, como a que descrevemos, é extremamente rara. Paciente do gênero feminino de 47 anos, há 8 meses com vegetação no mamilo direito. Ao exame, observa-se vegetação eritematosa de superfície anfractuosa e exulcerada medindo cerca de $2 \mathrm{~cm}$. Após exérese cirúrgica com margem de 2 $\mathrm{mm}$, o exame histopatológico mostrou imagem típica de siringocistoadenoma papilífero.

PALAVRAS-CHAVE - Mamilos; Neoplasias das Glândulas Sudoríparas.

\section{Syringocystadenoma Papilliferum of Atypical Location}

ABSTRACT - Syringocystadenoma papilliferum is a rare benign adnexal tumor, commonly located in the cephalic segment and usually associated with a sebaceous nevus. Clinically, it may resemble several neoplastic lesions, but histopathology is very characteristic. Surgical removal is the definitive treatment. The occurrence of this lesion on the nipple, as presented below, is extremely rare, although already described. A 47 years' old female patient reported a vegetating lesion on the right nipple, present for 8 months, occasionally with exudation. On examination, a vegetating nodule with a papillomatous and erosive surface measuring about $2 \mathrm{~cm}$ was observed adjacent to the nipple. Surgical excision with a narrow margin was performed. Histopathology showed the typical aspect of papillary syringocystoadenoma.

KEYWORDS - Nipples; Sweat Gland Neoplasms.

\section{INTRODUÇÃO}

O siringocistadenoma papilífero é um tumor anexial benigno raro, comumente situado no segmento cefálico e geralmente associado a um nevo sebáceo.' A sua localização na mama é um achado raramente relatado na literatura científica. ${ }^{2,3}$ Devido a esta raridade, reportamos um caso de uma mulher de meia-idade com siringocistadenoma papilífero nesta localização.

\section{CASO CLÍNICO}

Doente do sexo feminino, com 47 anos, fototipo IV, e queixas de nódulo na mama direita há cerca de oito meses com prurido discreto. Há aproximadamente dois anos, notou drenagem espontânea de secreção pelo mamilo direito, tendo sido prescrito antibiótico sistêmico sem qualquer benefício, porém evoluindo com regressão do quadro espontaneamente. Negava história de traumatismo local. A história médica pregressa e a história familiar não eram dignas de nota.
Ao exame, notou-se nódulo vegetante de superfície irregular e exulcerada, medindo cerca de dois centímetros e localizado no mamilo direito (Fig. 1). Mediante estes achados clínicos, realizou-se a exérese cirúrgica, para fins diagnósticos e terapêuticos, com margem de $2 \mathrm{~mm}$ sob anestesia local e sem intercorrências.

O exame histopatológico evidenciou a presença de invaginações ductais/quísticas estendendo-se profundamente na derme reticular, alternando com projeções papilíferas de epiderme acantótica e hiperceratótica (Fig. 2). As formações papilíferas apresentavam dupla camada de epitélio glandular, uma camada externa de células cuboides com núcleos redondos e citoplasma escasso e uma camada interna, dirigida para o lúmen dos ductos, e constituída por células cilíndricas com secreção por decapitação (Fig.s 3 e 4). No estroma, observava-se infiltrado inflamatório denso, superficial, perivascular e perianexial, misto, contendo numerosos plasmócitos (Fig. 4).
Correspondência: Thainá Gonçalves

Avenida Dalva, número 483

Marambaia - CEP: 66615-850

Belém, Pará, Brasil

E-mail: thainasgoncalves@gmail.com

DOI: https://dx.doi.org/10.29021/spdv.78.2.1139 2020/06/30

(C) Autor (es) (ou seu (s) empregador (es)) 2020 Revista SPDV. Reutilização permitida de acordo com CC BY-NC. Nenhuma reutilização comercial.

(c) Author(s) (or their employer(s)) 2020 SPDV Journal. Re-use permitted under CC BY-NC. No commercial re-use. 


\section{Caso Clínico}

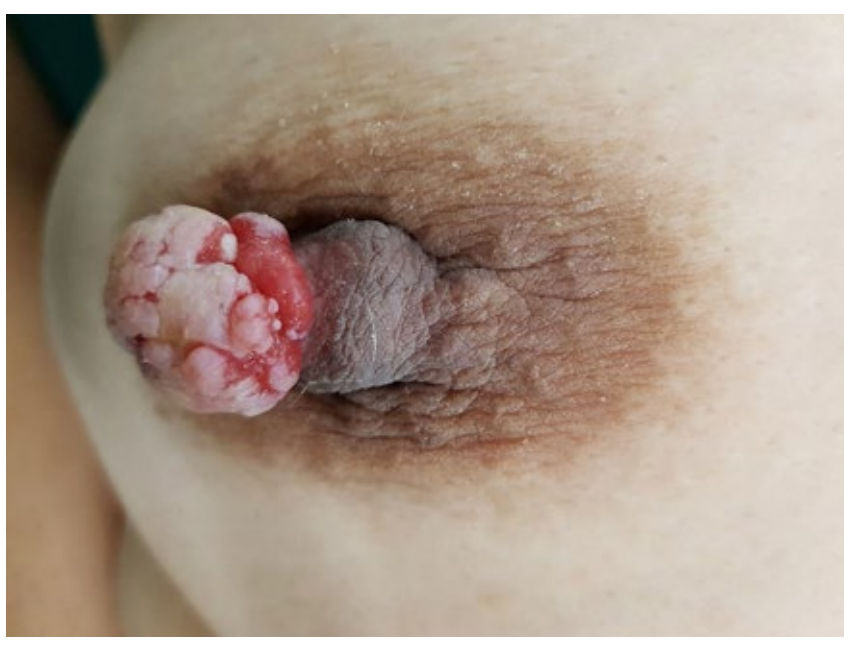

Figura 1 - Vegetação de superfície anfractuosa e exulcerada medin do cerca de $2 \mathrm{~cm}$ localizada no mamilo direito.

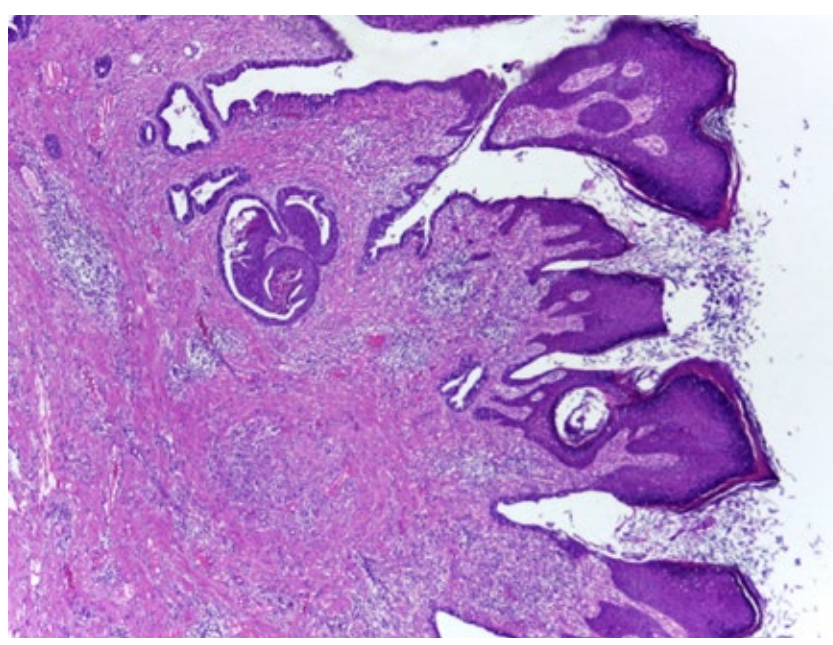

Figura 2 - Projeções papilíferas císticas, estendendo-se profundamente na derme reticular associada à epiderme acantótica e hiperceratótica $(\mathrm{H \& E}, \mathrm{x} 100)$.

Frente aos achados clínicos e histopatológicos, firmou-se o diagnóstico de siringocistadenoma papilífero (SCAP). A doente foi acompanhada por um ano sem evidências de recidiva.

\section{DISCUSSÃO}

O SCAP é uma neoplasia anexial benigna que surge a partir de células pluripotentes de glândulas apócrinas e écrinas. Sua histogênese ainda é controversa, sendo aceito a diferenciação predominantemente apócrina. ${ }^{1}$

Frequentemente ocorre na infância e na adolescência, sendo observado desde o nascimento em $50 \%$ dos casos. ${ }^{1-3}$ Localiza-se mais comumente no couro cabeludo, no pescoço e na face (75\%). ' Locais incomuns já relatados são: pálpebra, axila, nádega, pavilhão auricular, região escrotal, vulva, mamilo, dorso e abdómen. ${ }^{2,3}$ Essas localizações - que incluem a do presente caso - são muito raras. ${ }^{2,3}$

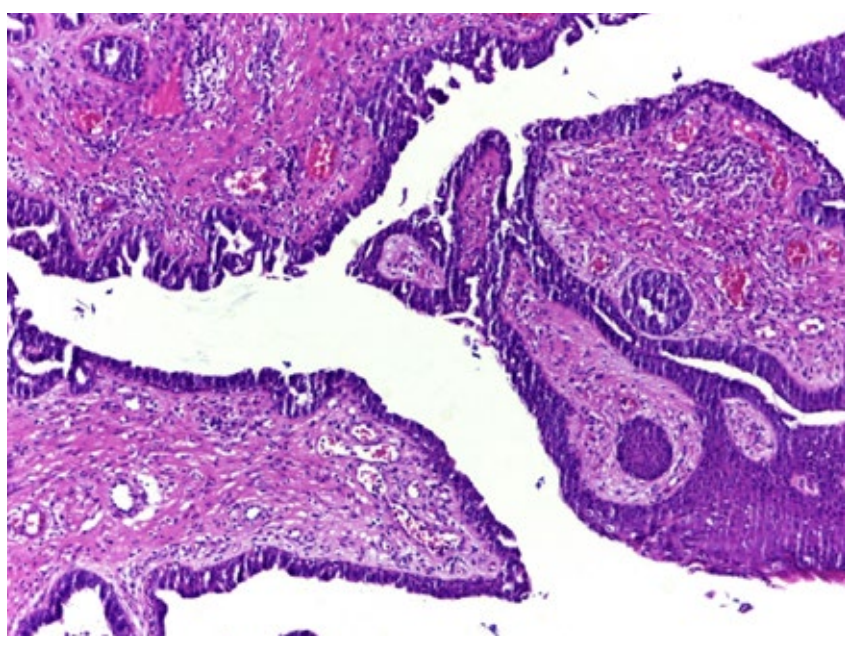

Figura 3 - Projeção papilar em detalhe. (H\&E, x100).

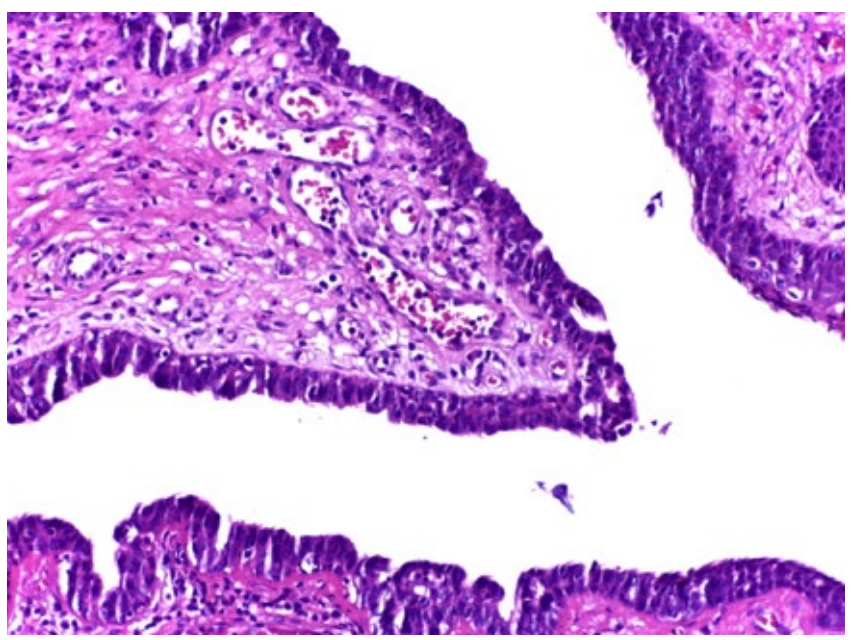

Figura 4 - Detalhe da projeção papilar evidenciando core rico em plasmócitos e secreção por decapitação (H\&E, x400)

Há descrições de uma ampla variedade de associações com outras neoplasias anexiais, como nevo sebáceo, hidrocistoma apócrino, siringoma de células claras, nevo apócrino, adenoma tubular apócrino e cistoadenoma apócrino. ${ }^{3}$

Clinicamente, trata-se de pápula, placa ou nódulo solitário. As apresentações com múltiplas lesões, configuração linear, ou de aspecto exsudativo são excepcionais. $\mathrm{Na}$ maioria dos casos, o SCAP é assintomático, podendo cursar com prurido, dor e hemorragia. A sua transformação maligna é excepcional. ${ }^{2,4}$

A histologia do SCAP é típica. Caracteriza-se por invaginações endofíticas epidérmicas na derme, formando estruturas ductais que alternam com formações papilomatosas. O epitélio é constituído por uma dupla camada característica que contém células cuboides com núcleos redondos e citoplasmáticos escassos na sua porção externa, e células cilíndricas com secreção por decapitação, na 


\section{Caso Clínico}

porção dirigida para o interior do lúmen. $\bigcirc$ estroma é rico em plasmócitos e linfócitos. ${ }^{4,5}$

A remoção cirúrgica é o tratamento definitivo. No entanto, em casos desfavoráveis à exérese, há relatos de tratamento eficaz com laser de $\mathrm{CO}_{2} .^{1,4}$

São poucos os relatos de localização incomum do SCAP pelo que apresentamos este caso de localização mamilar e que contribui para o diagnóstico diferencial de lesões vegetantes na mama.

Conflitos de interesse: Os autores declaram a inexistência de conflitos de interesse na realização do presente trabalho.

Fontes de financiamento: Não existiram fontes externas de financiamento para a realização deste artigo.

Confidencialidade dos dados: Os autores declaram ter seguido os protocolos da sua instituição acerca da publicação dos dados de doentes.

Consentimento: Consentimento do doente para publicação obtido.

Proveniência e revisão por pares: Não comissionado; revisão externa por pares.

Conflicts of interest: The authors have no conflicts of interest to declare.

Financing support: This work has not received any contribution, grant or scholarship.

Confidentiality of data: The authors declare that they have followed the protocols of their work center on the publication of data from patients.

Patient Consent: Consent for publication was obtained.

Provenance and peer review: Not commissioned; externally peer reviewed

\section{ORCID}

Thainá Gonçalves

https://orcid.org/0000-0003-4945-0937

Renata Cavalcante

https://orcid.org/0000-0001-7666-9761

Renata Okajima

https://orcid.org/0000-0003-2168-5515

Arival de Brito

https://orcid.org/0000-0002-7133-5321

Maraya Bittencourt

https://orcid.org/0000-0002-7297-0749

\section{REFERÊNCIAS}

1. Nascimento BM, Carneiro CM, Carvalho AH, Bittencourt MJ, Drago MG, Freitas LK. Siringocistoadenoma papilífero de localização atípica. An Bras Dermatol. 2015; 90: 899-901.

2. Bandyopadhyay D, Saha A, Kumar, D. Linear syringocystadenoma papilliferum on female breast: a rare appendageal tumour on an uncommon location. Dermatol Online J. 2014; 21.

3. Ghazeeri G, Abbas O. Syringocystadenoma papilliferum developing over hyperkeratosis of the nipple in a pregnant woman. J Am Acad Dermatol. 2014; 70: e84 - e85.

4. Einecke YS, Pinto EB, Silveira SO, Santos ML, Mendes $A D$, Carneiro FO. Siringocistoadenoma papilífero congênito. Re Soc Port Dermatol Venereol. 2018; 76 .

5. Shindo M, Yamada N, Yoshida Y, Yamamoto O, Morino S. Syringocystadenoma papilliferum on the male nipple. J Dermatol. 2011 ;38:593-6. doi: 10.1111/i.1346$-8138.2010 .01133 . x$. 